\title{
Los archivos de distrito en Portugal: memoria administrativa, histórica y social
}

\author{
Milena Carvalho* \\ Aurora González-Teruel ${ }^{\star \star}$
}

Artículo recibido:

29 de junio de 2016

Artículo aceptado:

14 de noviembre de 2016

\section{Resumen}

Se presenta un análisis de la evolución histórico-jurídica de los Archivos de Distrito (AD) portugueses, como instituciones que asumen la salvaguarda del patrimonio público-administrativo del país. Para ello se revisa la bibliografía más relevante sobre el tema, así como la documentación histórica, legal y política, describiendo su historia desde sus orígenes y los nuevos caminos que se van trazando, en relación con el aumento de la accesibilidad a la documentación que gestionan y a las nuevas estrategias de difusión de la información entre la ciudadanía. Todo ello en el marco de las distintas iniciativas de modernización administrativa y las nuevas tecnologías disponibles.

* Instituto Politécnico do Porto, Portugal.

milenacarvalho@eseig.ipp.pt

** Universidad de Valencia, España. agonzal@uv.es

INVESTIGACIÓN BIBLIOTECOLÓGICA, vol. 32, núm. 76, julio/septiembre, 2018, México, ISSN: 2448-8321 pp. 97-110 
Palabras clave: Archivos de Distrito; Portugal; Sistema Archivístico; Memoria Histórica.

\author{
District Archives in Portugal: administrative, historical \\ and social memory \\ Milena Carvalho, Aurora González-Teruel
}

\begin{abstract}
This article presents an analysis of the historical and legal evolution of the Portuguese Archives of District as institutions which take safeguard the country's public administrative documents. For this, the most relevant literature on the subject as well as historical, legal and political documents are reviewed, tracing its history from its origins, the new paths that are plotted in relation to the increased accessibility to the documentation, and new strategies for the dissemination of information to the public, also considering the context of the various initiatives of administrative modernization and new technologies.
\end{abstract}

Keywords: Archives of District; Portugal; Archival System; Historical Memory.

\title{
INTRODUCCIÓN
}

C e presenta un análisis histórico y jurídico de los archivos de distrito (AD) de OPortugal, con el fin de describir su importancia y evolución como garantes de la memoria histórica de un país. Su organización se debió a necesidades culturales inherentes a la sociedad de su momento, las necesidades de retención de capital y transmisión de la memoria, como una especie de adn de la complejidad social que se transmite de generación en generación: "El patrimonio hereditario de los individuos está inscrito en el código genético. El patrimonio cultural heredado está inscrito en primer lugar en la memoria de los individuos (cultura oral), después está escrito en las leyes, el derecho, los textos sagrados, la literatura y las artes” (Morin, 2003: 184). 
La conservación del patrimonio no parte de la protección simbólica de la memoria pasada, sino — desde la perspectiva de Guillaume (2003: 35) — también y principalmente desde una "heterología", en la medida en que asegura el recuerdo del pasado social, cultural y administrativo, además de que sustenta la posibilidad de un "futuro previsible". De acuerdo con Malheiro (2006: 16), surgen espacios propios y singulares, como bibliotecas, archivos y museos, con el fin de erigir grandes reconstrucciones del pasado.

Los AD surgen en un momento en el que se vio necesario relegar a las instituciones religiosas de la protección de la memoria institucional de Portugal. Con ello, la responsabilidad de salvaguardar la identidad administrativa del país. Así, apareció en Portugal, alrededor del siglo XIX, una visión emancipadora de la documentación que se concreta en un cambio desde una visión custodial y patrimonial con una connotación de tesoro, a otra visión poscustodial y abierta dominada por la búsqueda incesante de los contenidos o de la información (Malheiro, 2006: 18-19). Esto es algo que sólo comienza a consolidarse en el siglo XXI, sin embargo, el camino empezó mucho antes.

A continuación se presenta la trayectoria de la política archivística portuguesa, desde las primeras disposiciones legislativas, en las que los archivos van asumiendo el papel de registros de los derechos de las instituciones y de los ciudadanos, pasando por la necesidad de dotar de instrumentos de descripción que facilitaran el acceso a la información, hasta la situación actual, en la que, dada la revolución tecnológica, se presentan nuevos desafíos relacionados con el papel que los archivos en general y los $\mathrm{AD}$ en particular, que se deben asumir en la sociedad contemporánea. Se intenta poner de relieve (a nivel institucional no documental) la importancia histórica y jurídica de los $\mathrm{AD}$, así como los nuevos retos que los avances tecnológicos conllevan.

\section{Metodología}

Para describir la historia institucional de los $\mathrm{AD}$, se ha hecho una revisión de la legislación portuguesa de los siglos XIX y XX relacionada con los AD. Concretamente todas las disposiciones legislativas sobre la creación y evolución de los AD hasta la fecha, legislación generada en el marco de la transición de los archivos episcopales a los archivos públicos, así como la evolución de los archivos físicos a una nueva concepción de los archivos basados en conceptos tecnológicos. Se explora, además, la relación entre la ley que concibió los AD y las nuevas reglas de acceso a esta información, marcadas por la gestión documental en el contexto de una reestructuración de la administración central del Estado portugués. En el anexo 1 se proporciona el listado de la legislación más relevante citada en el artículo. 
Junto con la legislación, se han revisado diversos textos en el ámbito de la Ciencia de la Informacion de reciente publicación. En particular, este análisis está guiado por los textos de Ribeiro (1998), centrado en la información histórica y jurídica de los AD hasta 1998, y el de Carvalho (2014), que revisita la evolución histórico-institucional de los $\mathrm{AD}$, en el contexto de los requerimientos impuestos por las reformas administrativas y las necesidades empíricamente identificadas por los usuarios y profesionales de los archivos. Igualmente, se consideraron el trabajo de Sousa (2005) que analiza la evolución de los AD, así como el sitio web de la Direção-Geral do Livro, dos Arquivos e das Bibliotecas (DGLAB) y la del Arquivo Nacional Torre do Tombo (AN/TT) de Portugal.

\section{Fundación de los archivos De Distrito de Portugal}

Como afirma Cruz Mundet (1996: 402), los sistemas archivísticos son fiel reflejo de la organización política de un país, y también de su historia. En Francia, ejemplo del sistema archivístico centralizado (Shellenberg, 2004: 26), tras la Revolución francesa, se estableció una administración nacional de archivos públicos, llamada Archives Nationales. Se evidenció la importancia de los registros públicos a través de la puesta en marcha de una administración nacional independiente, la proclamación del acceso público a los archivos y la responsabilidad del Estado en el cuidado de los documentos administrativos (Shellenberg, 2004: 27). Sólo medio siglo más tarde, ocurrió en Inglaterra algo similar: la creación de un archivo central, el Public Record Office, en el contexto de un sistema archivístico descentralizado, cuyo objetivo era "restaurar el orden de los documentos públicos" (Shellenberg, 2004: 32).

En el caso de Portugal, igualmente su organización administrativa ha condicionado el devenir de la organización archivística. Los distritos portugueses se crearon en 1835 y constituyen la división administrativa del país. En la capital portuguesa residían la mayoría de competencias de la administración pública descentralizada, al menos hasta la transición a la democracia en 1974, cuando los municipios asumieron más competencias. Derivada de esta distribución territorial, surgieron los AD que se han mantenido hasta nuestros días, independientemente de los cambios posteriores en la distribución de competencias administrativas.

Desde 1916, cuando se fundó el Archivo de Leiria, hasta 1965, en que se fundan los últimos AD (cuadro 1), se presenta una serie de disposiciones normativas que conforman, poco a poco, el sistema archivístico territorial actual portugués, en general, y las competencias de este tipo de archivos, pieza clave de dicho sistema, en particular. 


\begin{tabular}{|c|l|}
\hline $\begin{array}{c}\text { Año de } \\
\text { creación }\end{array}$ & \\
\hline 1916 & Leiria \\
\hline 1916 & Bragança, Évora \\
\hline 1917 & Braga \\
\hline 1919 & Lisboa, Santarém1 \\
\hline 1931 & Porto, Coimbra (anexo al Arquivo da Universidade), Guimarães \\
\hline 1931 & Funchal \\
\hline 1931 & Ponta Delgada \\
\hline 1932 & Viseu \\
\hline 1933 & Portalegre \\
\hline 1948 & Angra do Heroísmo \\
\hline 1965 & $\begin{array}{l}\text { Aveiro, Beja, Castelo Branco, Faro, Guarda, Horta, Santarém, Setúbal, Viana do Castelo, } \\
\text { Vila Real. }\end{array}$ \\
\hline
\end{tabular}

Cuadro 1. Año de creación de los archivos de distrito de Portugal Fuente: Tombo.pt (2015)

No obstante, para que se legislara respecto de los $\mathrm{AD}$, es necesario señalar dos hitos: primero, el establecimiento de la República Portuguesa en 1910, y con ello la desaparición de numerosas prebendas que poseía la Iglesia católica, como la del registro de bautismos, matrimonios y defunciones, que pasó a ser competencia del Registro Civil, albergando, desde este momento, todo este patrimonio documental; el otro hito importante es la promulgación en 1911 (decreto del 18 de marzo de 1911, 1.213-1.215) del marco normativo que contempla la creación de los $\mathrm{AD}$, aunque por razones económicas no fueron puestos en marcha inmediatamente (Sousa, 2005: 69-80).

Para Ribeiro (1998: 600), el régimen republicano instaurado en $1910 \mathrm{fa}-$ voreció una nueva forma de pensar sobre la cultura, las bibliotecas y los archivos. Con ese espíritu surgió, el decreto del 18 de marzo 1911, mediante el cual se reorganizaron los servicios de bibliotecas y archivos, haciendo hincapié en el papel de conservación y mejora de los manuscritos para el estudio de la historia portuguesa, la incorporación de copias de los manuscritos portugueses ubicados en el extranjero, y el establecimiento, de manera pionera, de un horario de atención al público (Ribeiro, 1998: 703). De igual modo —de acuerdo con Ribeiro (1998: 592-593) —, esta ley abrió el Arquivo das Secretarias de Estado, con el fin de resolver el problema de los documentos acumulados provenientes de la administración central, de organismos extintos y documentos acumulados en los ministerios. Pero no se señalaban cambios significativos en cuanto a la transferencia de documentación entre los 
distintos tipos de archivos. Fue Júlio Dantas, a cargo de la Inspeção das Bibliotecas Eruditas e Arquivos, quien advirtió de la necesidad de crear otros archivos, lo que redundó en la primera iniciativa para el establecimiento de los AD en 1916. En dicho año se creó el AD de Leiria (decreto no. 2.550-J, 765-66 J), ${ }^{1}$ posteriormente el de Braganza (decreto no. 2.858, 1083-97) ${ }^{2}$ y el de Évora (decreto no. 2.859, 1096-97). ${ }^{3}$

Un añodespués, en 1917, se creó el AD de Braga (decreto no. 3.286, 615$53) ;^{4}$ y, en la práctica, el de Coímbra, como parte de los archivos de su universidad, asumiendo estas funciones desde 1917. En 1918, el propio Archivo Nacional Portugués pasó a asumir las funciones de AD de Lisboa e Santarém (artículo $12^{\circ}$ del decreto no. 4.312, 839-41).

Tiempo después, tuvo lugar una reforma más estructural de las bibliotecas y archivos, iniciada al poco tiempo de promulgada la primera ley del nuevo régimen de los servicios de bibliotecas y archivos en 1927. ${ }^{5}$ Como describe Ribeiro (2008: 9), el Ministerio de Educación designó un comité, presidido por Júlio Dantas, con el fin de preparar un nuevo proyecto de organización de los servicios de bibliotecas y archivos y, por tanto, de revisar la legislación anterior en ese rubro. Esta iniciativa no tomó forma de ley durante los tres años siguientes. Hasta que, en 1931, el decreto no. 19.952 estableció el marco legal determinante para la política archívística y bibliotecaria posterior. Dicha reforma tuvo un fuerte espíritu centralista y permitió ordenar la inspección "con mucha más extensa y fecunda ampliación de sus poderes" (decreto no. 19.952, 1253-69).

Con el decreto no. 19.952 se crearon los AD de Porto y Coimbra, así como el Archivo Municipal de Guimarães. Con ese mismo decreto (no. 19.952), corregido el 30 junio de 1931, se fundó el AD de Funchal; y en ese mismo año se creó el de Ponta Delgada (decreto no. 20.484, 2471-77). En 1932 se funda el de Viseu (decreto no. 20.803, 175-94) y dos años más tarde el de Portalegre, directamente subordinado a la Inspeção das Bibliotecas Eruditas e Arquivos, para "recoger, instalar, inventariar y facilitar la consulta a los estudiosos" (decreto no. 22.189, 173-76) de los documentos ahí depositados.

Tras un periodo de quince años, en 1948, se creó el Angra do Heroísmo (decreto no. 36.842, 315-17), directamente subordinado a la Inspeção

1 El Archivo del Distrito de Leiria se creó como un anexo de la Biblioteca Erudita de la misma ciudad

2 El Archivo del Distrito de Braganza se creó como un anexo de la Biblioteca Pública.

3 La referencia al Archivo del Distrito de Évora, así como la fijación de la Biblioteca Pública, de la cual la documentación, por cierto, ya se estaba reuniendo.

4 La relación con el Archivo del Distrito de Braga se creó y unió a la Biblioteca Pública.

5 Sobre el nuevo régimen de los servicios de bibliotecas y archivos en 1927, véase el decreto no. 13.724, 881-901. 
Geral das Bibliotecas e Arquivos. Diecisiete años después, en el decreto 46.350 (718-24), del 22 de mayo de 1965, se declaró con vehemencia en su preámbulo la necesidad de crear los AD restantes. En ese mismo texto se indicaba la creación de los archivos de Aveiro, Beja, Castelo Branco, Faro, Guarda, Horta, Santarém, Setúbal, Viana do Castelo y Vila Real (y la reapertura del AD de Braganza), ${ }^{6}$ completando la red de AD nacionales.

\section{DesarRollo de la política ARCHIVÍstica PORTUguesa}

\section{Y DE LOS ARCHIVOS DE DISTRITO}

Durante este periodo, se introdujeron varias disposiciones que afectaban a bibliotecas y archivos, como la extinción de la Inspeção Geral de Bibliotecas e Arquivos, pasando las competencias a la Direção Geral da Educação Superior e Belas-Artes (Carvalho, 2014: 108-109). Parafraseando a Ribeiro (1998: 627), el citado decreto no. 46.350 fue responsable de la valoración del "tratamiento técnico documental (trabajo de inventario y catalogación)”, y priorizó la "publicación de catálogos, inventarios, índices y rutas de los establecimientos [...]”. Además, se le empezó a dar importancia a la cualificación de los profesionales a cargo de los archivos y a la necesidad de generar herramientas de investigación para facilitar el control y difusión de los documentos (Carvalho, 2014: 108-109).

Así, en 1965, nuevas disposiciones legislativas (decreto no. 46.350, 72122) definían y expandían las competencias de los AD. No obstante, no fue hasta 1983, a través del decreto no. 149/83 del 5 de abril (decreto no. 149/83, 1150-52), cuando se definieron dichas competencias. Dicho decreto promulgaba la ley orgánica del Archivo Nacional de la Torre do Tombo, que le brindó autonomía administrativa, desvinculándolo de la tutela del Instituto Português do Património Cultural. Igualmente, reforzó el papel de los AD y las bibliotecas públicas como instituciones especializadas, señalando explícitamente las técnicas de procesamiento de los fondos documentales, por ejemplo, la normalización de los procedimientos de inventario, clasificación e indización, así como la vertiente más orientada hacia el usuario (decreto no. 149/83, 1151). Además, estipulaba en el artículo $2^{\circ}$ nuevas instrucciones para las transferencias (decreto no. 149/81, 1150-51).

6 "O presente decreto-lei completa por isso a rede dos arquivos distritais, criando, de harmonia com o disposto nos artigos $27^{\circ}$ e seus $1^{\circ}$ e $2^{\circ}$ e $28^{\circ}$ do Decreto $n^{\circ} 19952$, no $n^{\circ} 1$ do artigo $313^{\circ}$ do Código Administrativo (redacção do Decreto-Lei n ${ }^{\circ} 42536$ ) e no n ${ }^{\circ} 6$ do artigo $24^{\circ}$ do Estatuto dos Distritos Autónomos, os Arquivos de Aveiro, Beja, Castelo Branco, Faro, Guarda, Horta, Santarém, Setúbal, Viana do Castelo e Vila Real, ao mesmo tempo que promove a reabertura do de Bragança” (decreto no. 46.350, 719). 
Este decreto, promulgado en 1983, junto con otros publicados en años posteriores (decretos no. 447/88, 16/93 y 60/97; ley 107/2001) hasta el año 2001, conformaron la obligación de incorporar en los archivos públicos la documentación histórico-cultural de interés nacional e internacional, así como tipificar qué documentación debe incorporarse al AD. Se trata de la documentación del registro civil, registros parroquiales, registros notariales, tribunales, servicios desaparecidos y todos los demás documentos que, según la ley, deben recoger los AD (decreto no. 149/83, 1151). No obstante, fue en 2004 (decreto no. 47/2004, 1161-62), cuando se concretó la naturaleza de las "incorporaciones obligatorias", pues definió con precisión en qué archivos debían estar. Así, sin perjuicio de la legislación vigente en ese momento (decreto no. 149/83) se determinó que eran de "incorporación obligatoria" en los AD y equiparados:

a) La documentación producida por los servicios de la administración central descentralizada de la respectiva área.

b) La documentación producida por las empresas públicas situadas en la zona geográfica correspondiente a su sede.

c) La documentación producida por las empresas públicas en proceso de privatización o cese del área geográfica correspondiente a su sede.

d) Los servicios de archivos extintos y documentación proveniente de funciones extintas en de servicios y organismos de la administración central descentralizada del área respectiva [...]” (decreto no. 47/2004, 1161-62).

En el plano de la asunción de competencias por parte de la administración pública portuguesa, en 1992, con la fusión del Instituto Português de Arquivos (ipa) y el principal Archivo Nacional del Estado, el de Torre do Tombo (decreto no 106-G/92, 1150-52), apareció un nuevo organismo, el Arquivo Nacional/Torre do Tombo (IAN/ITT), que sería supervisado por el Ministerio de Cultura. Desde 1997 (decreto no. 60/97, 1276-83), éste se encarga de promover y ejecutar la política nacional de archivos en materia de conservación y mejora de la documentación, la promoción de la calidad de los archivos actuales, así como la salvaguarda y garantía de los derechos del Estado y los ciudadanos (Penteado, ed., 2006: 7). La identidad del organismo fue restaurada en 2012, con la publicación de la Lei Orgânica da Direcção Geral do Livro, Arquivos e Biblioteca (dglab) (decreto no. 103/2012, 2535-37), que plantea, en el contexto del Plano de Melhora e Redução da Administração Central (PREMAC), un conjunto de tareas básicas para la DGLAB (preámbulo del decreto no. 126-A/2011, 5516-[2]). 
En ese contexto, el AD de Lisboa se reintegró al de Torre do Tombo y el Archivo Nacional de Torre do Tombo se convirtió en un servicio nuclear integrado en la Dirección General (IAN/ITT, 2015). Desde entonces, el Arquivo Nacional/Torre do Tombo es una unidad orgánica de la Dirección General del Libro, Archivos y Bibliotecas (DGLAB) (ordenanza no. 192/2012, 3039-42; orden no. 9339/2012, 24380-24381).

Otro caso particular es el de los archivos públicos de las Regiões Autónomas dos Açores, con base en las tres principales ciudades del archipiélago: Ponta Delgada, Angra do Heroísmo y Horta (AD creados en 1931, 1948 y 1965, respectivamente). Éstos surgieron tras una política de descentralización y están subordinados a la Inspeção Geral das Bibliotecas e Arquivos. Respecto de las Azores, tanto la Constitución de la República de Portugal, como su Estatuto Político-administrativo dictan la capacidad de legislar sobre asuntos de interés específico, lo que significa que se puede (y debe) establecer una política de archivos regional. Sin embargo, en la práctica, la legislación nacional dictada hasta 1993 (decretos nos. 447/88, 121/92 y 16/93) ha sido el marco normativo de esta región hasta 2007 (Carvalho, 2014: 154). Entre 2007 y 2008, se promulgaron dos decretos regionales que, según Sousa et al. (2011: 78-86), establecieron un nuevo modelo estructural y funcional de sus archivos bajo la dirección de la administración pública regional.

\section{LOS ARCHIVOS DE DISTRITO EN LA ACTUALIDAD}

En los últimos tiempos, los $\mathrm{AD}$ han sido objeto de nuevos cambios, algunos de carácter tecnológico operados por la Web 2.0 (y Web 3.0); otros, debidos a la modernización de la administración pública y a la aplicación de criterios de racionalidad económica, así como cambios relacionados con la mejora de la accesibilidad y la conservación digital de los archivos. Hoy en día, las reflexiones sobre su futuro convergen hacia un punto: de qué manera serían más funcionales e interactivos, con el fin de facilitar el acceso y uso por parte de los ciudadanos, sus potenciales usuarios.

Para Sousa et al. (2011: 78-86), a partir de 2010, en el contexto de la reforma del gobierno portugués, los $\mathrm{AD}$ ganan protagonismo "no porque la ordenanza que consigna sus facultades (decreto no. 149/83) haya sufrido algunos cambios [...], sino debido a que las reformas en curso requieren un replanteamiento de la misión de estos archivos que no puede reducirse a la preservación del patrimonio archivístico adquirido".

Evidencian que la ley que establece la estructura de los archivos de la Dirección General (DGARQ) no hace referencia a los deberes de los AD, y la 
ordenanza no. 372/2007, que determina la estructura nuclear de los servicios y la preparación de las unidades organizativas de dgarq, asigna a los AD de Leiria y Porto competencias que no anulan las mencionada en el decreto no. 149/83. Sin embargo, fue el Proceso de Reestructuración de la Administración Central del Estado (PRACE) el que supuso una oportunidad para la modernización de la administración pública y del uso de los medios necesarios para su funcionamiento, "intentando adaptar la estructura organizativa y funcional del Estado a los procesos necesarios para la vida de la nación” (Sousa et al., 2011: 78-86). Para estos autores, aún hay un defecto en este sistema: es necesario definir mejor la política de los AD dependientes de la dgarq. Entre otras directrices, el prace alude a la externalización de la gestión y mantenimiento de los archivos físicos y digitales de los recursos comunes y compartidos, y muestra los beneficios futuros de esta externalización. No obstante, esa medida es preocupante para el futuro de los AD, en la medida en que está por verse si el sector privado posibilitará, de manera óptima, la consecución de sus objetivos y las implicaciones en términos de costes de transacción.

En lo que respecta al futuro de los $\mathrm{AD}$, ciertamente que han asumido nuevas funciones, no previstas inicialmente en la legislación. Un ejemplo de ello es el proyecto del Repositorio de Objetos Digitáis Autênticos (RODA), creado en 2007 con el fin de promover un estudio de la viabilidad acerca de diversos aspectos de la preservación de objetos digitales. En esencia, este proyecto propone lograr una solución tecnológica capaz de incorporar, describir y dar acceso a todo tipo de información digital producida en el contexto de la administración pública. Desde entonces ha estado vinculada a la Rede Portuguesa de Arquivos (RPA) para apoyar la integración de bases de datos relacionales, texto estructurado, imágenes fijas y sonido (RODA, 2015).

De hecho, los AD actualmente desarrollan estrategias de intervención activas para la preservación documental de archivos familiares, personales y empresariales que, por su relevancia cultural y social, deben conservarse de manera permanente (Sousa et al., 2011: 78-86). Además, otra área hacia la que parecen dirigirse es la expansión cultural y educativa, a través de exposiciones con orientación pedagógica y la divulgación de información histórica y administrativa nacional. En este sentido, Nogueira (2012: 30) destaca la importancia de la exposición documental como medio de difusión del patrimonio archivístico. Cada vez se asocia más la problemática de los AD con las cuestiones relacionadas con los aspectos de mediación de la información en ellos contenida. 


\section{Conclusiones}

Los AD en Portugal se crearon para proteger la documentación administrativa nacional, cumpliendo así un papel fundamental en la preservación de la memoria del país. Ello favoreció la evolución desde un modelo secular de la documentación de archivo, hacia otro basado en la accesibilidad y usabilidad (cada vez más interactivos), orientados a la difusión de los fondos documentales de cada región y la disponibilidad entre sus ciudadanos.

La historia político-legal y jurídica indica que este proceso fue largo, lento y, en ocasiones, arduo. Igualmente, la historia de la evolución de los AD indica que en la actualidad este proceso aún está lejos de consolidarse. Aún persisten nuevos desafíos que la legislación debe resolver, en la medida en que todavía se basa en un modelo de archivo más como repositorio, sin contemplar de lleno su vertiente comunicativa. Todo ello, por otra parte, también se concreta en la necesidad de formación e interdisciplinariedad de los profesionales de los archivos.

Otro aspecto es el relacionado con la capacidad física de las instituciones para albergar todos los documentos en las condiciones adecuadas. Tras su creación, gran parte de los AD cambiaron de ubicación hasta su sede definitiva, procedimiento que inició en 1835 y se consolidó a partir de la fundación de la primera república, un proceso caracterizado por la creación de las oficinas de registro civil, debido a la necesidad del control demográfico del país.

Así, las oficinas del Registro Civil dieron cabida a toda la documentación administrativa nacional y municipal. Oficialmente, fue hasta 1911 cuando los AD se convertirían en los guardianes de estos fondos: manuscritos originales de las instituciones religiosas y monárquicas en todo el país, colecciones de archivos del gobierno local y algunos servicios estatales. La democracia en Portugal no cambió excesivamente esta situación.

A pesar del anuncio de la disolución de los distritos en diversos momentos de la historia, el hecho es que esto no fue así, manteniéndose hasta la actualidad la figura de los AD. Todos respondieron a la necesidad de descentralización administrativa; aunque su situación no se estabilizó hasta 2012, con la DGLAB.

Hoy, los AD aspiran a incorporar las últimas soluciones de usabilidad y la modernización administrativa, a fin de facilitar a los ciudadanos la consulta de los documentos administrativos óptima y simplificadamente. Así, se integran las últimas soluciones tecnológicas que facilitan el acceso y la reproducción de la documentación histórico-administrativa, proporcionando una contribución educativa irrenunciable, tanto para la narración de la historia, como de la cultura contemporánea, a través, en parte, de los planes de difusión cultural. 
Indudablemente que una mayor difusión de estas iniciativas por parte de los AD generará mayor conciencia, conocimiento y reconocimiento, asimismo garantizará la protección de la historia administrativa de las colecciones de la comunidad y de los documentos a su cuidado. Este punto de vista se combina con algunas preocupaciones prácticas y éticas relacionadas con el uso del outsourcing en la gestión de los archivos y el modo como se protege la integridad del manuscrito en los procesos de digitalización y a qué desafíos se enfrenta el profesional de los archivos en Portugal. El proyecto RODA aparece como una solución tecnológica prototipo para simplificar el desarrollo y el acceso a la información de la administración pública. Al estar relacionado con el rpa, permitiría un resultado que podría ser replicado en otros AD. Sin embargo, este objetivo está todavía lejos de ser una realidad.

\section{REFERENCIAS}

Arquivo Nacional/Torre do Tombo (IAN/ITT). 2015. "História". <http://antt.dglab. gov.pt/inicio/identificacao-institucional/6-2/>, visitado el 9 de diciembre.

Carvalho, Milena. 2014. "Estudo da mediação e do uso da informação nos Arquivos Distritais". Coimbra: Universidade de Coímbra, Ph.D. diss.

Cruz Mundet, José Ramón. 1996. Manual de Archivística. Madrid: Fundación Germán Sánchez-Ruipérez.

Guillaume, Marc. 2003. A política do património. Porto: Campo das Letras Editores.

Heredia Herrera, Antonia. 1991. Archivística general. Teoría y práctica, $5^{a}$ ed. Sevilla: Diputación Provincial de Sevilla.

Jardim, José Maria. 2015. "Obstáculos à construção de políticas nacionais de arquivos no Brasil e na Espanha: uma abordagem teórico-metodológica de análise". Revista Liinc 1: 197-213. <http://www.ibict.br/liinc>, visitada el 8 de noviembre.

Malheiro da Silva, Armando. 2006. A informação. Da compreensão do fenómeno e construção do objecto científico. Lisboa: Edições Afrontamento.

Malheiro da Silva, Armando y Fernanda Ribeiro. 2010. Recursos de informação. Serviços e utilizadores. Lisboa: Universidade Aberta.

Morin, Edgar. 2003. O método V. A humanidade da bumanidade: a identidade bumana. Mem Martins: Publicações Europa América.

Nogueira, Marta. 2012. "A difusão cultural no Arquivo Nacional e Arquivos Distritais Portugueses: exposições documentais (1990-2009)". Évora: Universidade de Évora, Master diss.

Penteado, Pedro (ed.). 2006. Orientações para a gestão de documentos de arquivo. No contexto de uma reestruturação da administração central do Estado. Lisboa: Instituto dos Arquivos Nacionais/Torre do Tombo.

Repositório de Objetos Digitáis Autênticos (RODA). 2015. <http://arquivos.dglab. gov.pt/servicos/arquivo-digital-roda/>, visitado el 8 de noviembre. 
Ribeiro, Fernanda. 2008. "A Inspeção das Bibliotecas e Arquivos e a Ideologia do Estado Novo”, em Luís Reis Torgal e Heloísa Paulo, eds., Estados autoritários e totalitários e suas representações: propaganda, ideologia, historiografía e memória, 223237. Coimbra: Universidade de Coímbra.

Ribeiro, Fernanda. 1998. "O acesso à informação nos arquivos". Porto: Universidade do Porto, Ph.D. diss.

Shellenberg, Theodore. 2004. Arquivos modernos. Princípios e técnicas. Rio de Janeiro: FCV Editora.

Sousa, Acácio de. 2005. "90 años. Los Archivos de Distrito de Portugal”. Tabula: Revista de Archivos de Castilla y León 8: 69-80

Sousa, António, Maria João Pires de Lima y Olinda Cardoso. 2011. "Arquivos Distritais: a perspectiva de uma nova missão?". BAD-Atas do Congresso Nacional de Bibliotecários, Arquivístas e Documentalistas 10: 78-86, en <http://www.bad.pt/publicacoes/index.php/congressosbad/article/view/176/172>, visitada en noviembre 8,2015 ,

Sousa, António, José Carlos Ramalho, Luis Miguel Ferros y Maria João Pires de Lima. 2007. "Consulta real em ambiente virtual: implementação de uma sala de referência e leitura virtual num arquivo". Atas do Congresso Nacional de Bibliotecários, Arquivístas e Documentalistas 9: 1-7, en <http:/www.bad.pt/publicacoes/ index.php/congressosbad/article/view/557/364>, visitada el 17 de noviembre.

Sousa, Fátima. 2012. "Políticas para a gestão de informação arquivística: os Arquivos Centrais da Administração Pública dos Açores”. Lisboa: Universidade de Lisboa, Master diss.

Tombo.pt. Registos paroquiais portugueses para genealogia. 2015. "Historia dos arquivos portugueses”. <http://tombo.pt/content/historia-dos-arquivos-portugueses>, visitado el 8 de noviembre.

\section{Anexo 1. Fuentes legislativas}

Diário do Govêrno

Decretos

De 18 de Março de 1911. Diário do Govêrno. Lisboa. 65 (21 Mar.1911). 1213-1215.

N².550-J. Diário do Govêrno. $1^{\text {a }}$ série. 154 (3 Ago. 1916) 765-766J.

№ 2.858. Diário do Govêrno. $1^{a}$ série. Lisboa. 242 (29 Nov. 1916) 1096.

N² 2.859. Diário do Govêrno. 1ª série. Lisboa. 242 (29 Nov. 1916) 1096-1097.

No 3.286. Diário do Govêrno. $1^{\mathrm{a}}$ série. Lisboa. 132 (11 Ago. 1917) 647.

№ 4.312. Diário do Govêrno. $1^{a}$ série. Lisboa. 117 (29 Maio 1918) 839-841.

No 13.724. Diário do Govêrno. $1^{a}$ série. Lisboa. 114 (3 Jun. 1927) 881-901.

No 19.952. Diário do Govêrno. 1ª série. Lisboa 147 (27 Jun. 1931) 1253-1269.

N²0.484 Diário do Govêrno, (6 Nov. 1931 ) 2471-77.

N²0.803 Diário do Govêrno, 175-94.

N²2.189 Diário do Govêrno, 173-76.

N³6.842 Diário do Govêrno, 315-17.

N 46.350 Diário do Govêrno, 718-24.

№ 19 952, no n¹ do artigo $313^{\circ}$ do Código Administrativo (redacção do Decreto-Lei nº 42 536).

N 46.350 del Diario del Gobierno, 721-22. 
No 149/8I del Diario del Gobierno, 1150-51.

№ 447/88. Diário da República. Série l. 284 (1988 dic 10). 4885.

№ 126-A/2011 del Diario del Gobierno, 5516-(2).

Decretos-ley

Decreto-Lei n 149/83. Diário da República. Serie I. 78 (1983 abril 5), 1150-1152.

Decreto-Lei n. ${ }^{0}$ 16/93. Diário da República. I-A Série. 19 (1993 enero 23), 264-270.

Decreto-Lei n. ${ }^{\circ}$ 60/97. Diario da Republica. 1 Série A. 67 (1997 Mar. 20), 1276-1283.

Decreto-Lei nº 149/83. Diário da República. Serie I. 78 (1983 abril 1983), 1150-1152.

Decreto-Lei nº 47/2004. Diári o da República. Série I-A. 53 (Marzo 2004), 1161-1162.

Decreto-Lei n. ${ }^{\circ} 106-G / 92$. Diário da República. Suplemento I-A Série. 126 (1992 jun. 01), 39-45.

Decreto-Lei n 103/2012. Diário da República. Série I. 95 (2012 May 16), 2535-37.

Decreto-Lei n. ${ }^{\circ}$ 447/88. Diário da República. I Série. 284 (1988 Dic. 10), 4885.

Decreto-Lei n. ${ }^{\circ}$ 121/92. Diário da República. I-A Série. 150 (1992 Set. 02), 3146-3147.

Leyes

Lei nº 107/2001. Diário da República. Série I . A. 209 (2001 sept 8), 5808-5829.

Órdenes

Orden № 9339/2012, 24380-24381 del Diario del Gobierno.

Ordenanzas

№ 192/2012, 3039-42.

No. 372/2007, 30 de marzo.

Para citar este texto:

Carvalho, Milena y Aurora González-Teruel. 2018. "Los archivos de distrito en Portugal: memoria administrativa, histórica y social”. Investigación Bibliotecológica: archivonomía, bibliotecología e información 32 (76): 97-110. http://dx.doi.org/10.22201/iibi.24488321xe.2018.76.57983 